\title{
Mudança na Estrutura Argumental dos Predicados da Língua Katukina-Kanamari
}

\author{
Change in the Argumental Structure \\ of the Predicates of Katukina-Kanamari Language
}

\begin{abstract}
Zoraide dos Anjos
Universidade Federal de Roraima (UFRR)
\end{abstract}

Manoel Gomes dos Santos

Universidade Federal de Roraima (UFRR)

\begin{abstract}
Resumo. Este trabalho tem o objetivo de apresentar alguns dos processos que modificam a estrutura argumental dos predicados na língua indígena amazônica Katukina-Kanamari (katkan) falada no sudoeste do estado do Amazonas, Brasil por cerca de 2.700 pessoas. Foram identificadas duas grandes variedades para essa língua: Katukina do Biá, falado pelos membros da etnia de mesmo nome que habitam as margens dos rios Jutaí, Biá e Ipixuna; e, Kanamari composta por aproximadamente 1.90o indivíduos na Terra Indígena Vale do Javari e regiões vizinhas. O artigo está organizado em duas seções. Na primeira delas, apresentamos, de maneira breve, as classes lexicais nessa língua que figuram como núcleo da predicação, que são os nomes, verbos, advérbios e posposições. Em seguida descrevemos os predicados de tipo bivalente e monovalente assim como suas estruturas internas. A segunda parte do artigo é dedicada aos processos de mudança argumental. Destacamos três que decrescem a valência: intransitivização, reflexivo e recíproco que utilizam o sufixo -hik.
\end{abstract}

Palavras-chave: Mudança de valência; Predicados; Katukina-Kanamari.

Abstract. This work aims to present some of the processes that modify the argument structure of predicates in the indigenous Amazonian language katukina-kanamari (katkan) spoken in the southwest of state of the Amazonas, Brazil by about 2,70o people. Two major varieties have been identified for this language: Katukina do Biá spoken by members of the same name who live on the banks of the Jutaí, Biá and Ipixuna rivers; and kanamari composed of approximately 1,900 indivuduals in the Vale do Javari and neighboring regions. The paper is organized in two sections. In the first one, we briefly present the lexical classes in that language that are at the core of the predicates, which are names, verbs, adverbs and postpositions. Then we describe the predicates of bivalent and monovalent type as well as their internal structures morphological aspects of the lexical classes in that language which appear as core of the predication: names, verbs, adverbs and postpositions. The second part of the paper is dedicated to the processes of argument change. We highlight three processes that decrease valence: intransitivization, reflective and reciprocal.

Keywords: Change valence; Predicates; Katukina-Kanamari.

\section{Introdução}

A língua katukina-kanamari é falada por cerca de 2.700 pessoas no sudoeste do estado do Amazonas, Brasil. De acordo com os trabalhos linguísticos mais recentes (vide ANJOS, 2019; ISHY, 2018), estão documentadas duas grandes variedades nessa língua: Katukina do Biá e Kanamari. A variedade 
Katukina é falada pelos membros da etnia de mesmo nome que habita as margens do Rio Jutaí, afluente do lado esquerdo do rio Solimões cuja população é de aproximadamente 800 pessoas. Ao que parece, essa é a única língua ainda existente daquelas que constituem a família linguística Katukina.

Este artigo, que descreve as mudanças estruturais nos predicados dessa língua, está dividido em duas partes. A primeira delas é dedicada à apresentação dos predicados bivalentes e monovalentes, a saber: estrutura, características dos argumentos nucleares. Os mecanismos que decrescem a valência, a saber: intransitivização, reflexivo e recíproco são o tema da segunda parte desse trabalho.

Antes de apresentar as classes lexicais do Katukina-Kanamari, doravante katkan, é necessário definirmos alguns dos conceitos utilizados neste artigo.

O termo sintagma refere-se a uma palavra ou um grupo de palavras funcionando como um bloco em determinado nível da estrutura. A oração designa o conjunto constituído por um predicado com argumentos ou não (tais como os predicados nominais existenciais). Por fim, o termo argumento é utilizado para designar apenas os elementos nucleares.

\section{Classes léxicas e a posição nuclear nos predicados}

Existem quatro classes de palavras nessa língua: nomes, verbos, posposições e advérbios. A habilidade de um vocábulo ocupar a posição nuclear em sintagmas e predicados é o critério de identificação utilizado na definição das classes léxicas em katkan.

Convém ressaltar que uma palavra ao funcionar como núcleo tem como tendência apresentar distribuição sintática parecida a do constituinte do qual ela é núcleo (cf. CREISSELS, 2001). As classes nominais, verbais e posposicionais são classificadas como flexionáveis e os advérbios são inflexionáveis. Com o critério de identificação a partir da posição nuclear, constatamos que há três os tipos básicos de predicados: nominal, verbal e adverbial ${ }^{1}$.

A partir do número de argumentos requeridos pelo núcleo do predicado, há dois tipos de predicação: (1) monovalente e (2) bivalente. É importante salientarmos que os núcleos em katkan instituem predicados sem a exigência de cópula.

Adotamos, também, a análise de Queixalós (2005, 2013, 2019) sobre valência dos nomes. Para o autor, assim como os verbos, os nomes estão habilitados a selecionar argumentos para a saturação da valência. Por esta razão, nomes monovalentes (ou alienáveis) selecionam um argumento, ao passo que nomes bivalentes (ou inalienáveis) necessitam de dois argumentos para que sua valência seja satisfeita.

De maneira semelhante, predicados cujos núcleos são advérbios e posposições estão habilitados a instituir, respectivamente, valência mono e bivalente.

\section{Predicados: características básicas}

Nas seções seguintes, apresentaremos as características básicas de cada predicado bem como sua estrutura interna.

1. O predicado posposicional é analisado como um subtipo do predicado adverbial. 


\section{Predicados monovalentes}

Nesse tipo de predicação, existe um argumento externo ao núcleo em termos de constituência como é possível verificar, nos exemplos seguintes, em que predicados monovalentes estão delimitados entre colchetes:

[dadohi] piya
correr homem
"O homem correu".

(2)

[mimina] adu

mulher não indígena 1 SG

"Eu sou não indígena". (Lit: eu sou branca)

(3)

$\begin{array}{ll}\text { [tanti] } & \text { pi:da } \\ \text { Aqui } & \text { onça }\end{array}$

"A onça está aqui".

A posição nuclear é ocupada por um verbo monovalente (1), um nome inalienável (2) e um advérbio (3), respectivamente: dadohi "correr", mimina "mulher não indígena" e tanti "aqui". À direita do núcleo está o argumento externo, a saber: piya "homem" em (1), adu "eu" em (2) e pi:da "onça" em (3).

Assumimos como ordem canônica dos predicados monovalentes a sequência núcleo-argumento externo. Contudo, é possível identificar construções com esse argumento à esquerda do núcleo:

$$
\begin{array}{ll}
\text { piya } & \text { [dadohi] } \\
\text { correr } & \text { homem } \\
\text { "O homem correu". }
\end{array}
$$

Convém pontuar que não encontramos condicionamento que explique esse movimento do argumento externo até o presente momento. Contudo, em pesquisas futuras, o contato dos falantes katkan com a língua da sociedade emergente (português) deve ser considerado como ponto de partida para hipotetizar acerca de explicações plausíveis para o movimento aqui descrito.

\section{Predicados bivalentes}

Neste tipo de predicação, o núcleo está habilitado a selecionar dois argumentos: um interno ao predicado e outro externo. Essa construção é a mais complexa que a do tipo monovalente. A posição nuclear é ocupada por um verbo bivalente (4), por um nome inalienável (5) ou por uma posposição (6) e seus respectivos dependentes como demonstram os exemplos extraídos de textos coletados com falantes dessa língua:

$\begin{array}{lll}\text { (4) Tirin-na }= & \text { hu:na kamodya } & =k a \\ \text { Tirin } & \text { pegar macaco barrigudo } & \text { PERF } \\ \text { "Tirin pegou o macaco barrigudo". } & \end{array}$


(5)

$\begin{array}{lll}\text { Kontan-na }= & \text { ponhanya } & \text { Ka:ko } \\ \text { Kontan-GEN f } & \text { ilha } & \text { Ka:ko }\end{array}$

"Ka:ko é filha de Kontan".

(6)

$\begin{array}{lll}\text { [Ba:da-na }= & {[\text { katu] }]} & \text { Dyoraidi } \\ \text { Ba:da-OBJPOSP } & \text { INS } & \text { Dyoraidi }\end{array}$

"Dyoraidi está com Ba:da".

Nos exemplos apresentados, o argumento interno ao núcleo das construções bivalentes está expresso por um sintagma nominal, respectivamente Tirin; Kontan e Ba:da, marcado para caso por meio do enclítico -na= que indica os casos estruturais ergativo, genitivo e objeto de posposição, nessa ordem.

Convém dizermos, ainda, que a notação aqui utilizada para o clítico, isto é, -na= é pouco usual e foi utilizada, anteriormente, somente por Francesc Queixalós, linguista que estuda as línguas da família Katukina desde meados dos anos 1990. Nos parece oportuno utilizar essa notação uma vez que expressa a relação gramatical do sintagma nominal precedente, assim como indica a procliticização, no nível prosódico, do marcador de caso estrutural ao núcleo que o sucede.

Entretanto a análise acerca da marcação casual, aqui utilizada, difere da proposta de Queixalós (2005, 2007, 2010) na qual o enclítico $-n a=$ indica Caso Marcado (CM). Assumimos a ideia de que $-n a=$ é um clítico multifuncional e em cada tipo de predicado há um tipo distinto de relação estabelecida entre o núcleo e seu argumento interno. Por essa razão, estabelecemos rótulos distintos. Dessa forma, em um predicado cujo núcleo é um nome inalienável, a exemplo de (5), a relação entre o núcleo e seu dependente é de natureza genitiva. Em predicados com posição nuclear ocupada por um verbo bivalente (exemplo 4), a relação estabelecida com o dependente é ergativa. Por fim em predicados com núcleo posposicional, a relação estabelecida ocorre entre posposição e seu objeto tal qual em (6).

No que se refere ao argumento externo nesses predicados, esse é formado por um sintagma nominal sem marcação morfológica. De acordo com Anjos (2011; 2019), assim como os nomes plenos, as subclasses nominais (pronomes livres, demonstrativos, possessivos, numerais, entre outros) ocupam a posição nuclear e selecionam -na=.

Todavia, quando o argumento interno de um sintagma verbal bivalente, de um sintagma de nome inalienável ou de um sintagma posposicional não for expresso lexicalmente, isto é, mediante sintagma formado por [NOME-CASOESTRUTURAL], sua representação será feita por meio do paradigma de prefixos pessoais que remetem aos referentes antes representados lexicalmente:

Paradigma de prefixos pessoais

\begin{tabular}{|c|c|c|}
\hline & Singular & Plural \\
\hline 1 & yok- & tyo- \\
2 & no- & na- \\
3 & ha- & ma- \\
\hline
\end{tabular}

Fonte: (adaptado de ANJOS, 2011, p. 126) 
$\left(4^{\prime}\right)$

$\begin{array}{ll}\text { ha-hu:na kamodya } & =k a \\ \text { 3SG-pegar macaco barrigudo } & \text { PERFEC } \\ \text { "Ele pegou o macaco barrigudo". } & \end{array}$

(5') ha-ponhanya Ka:ko

3SG-filha Ka:ko

"Ka:ko é filha dele".

$\left(6^{\prime}\right)$
ha-katu Dyoraidi
3SG-INSTR Dyoraidi
"Dyoraidi está com ela".

Ao substituir o sintagma nominal marcado para caso por uma das formas do paradigma prefixal, bloqueia-se, automaticamente, a associação do enclítico -na=. De acordo com os dados por nós analisados, a forma PREF-na= resulta em construções agramaticais.

\section{Predicados monovalentes}

Essa é uma forma mais simples do que a apresentada na predicação bivalente. Nesse caso a posição nuclear é preenchida por um verbo monovalente (7), um nome alienável (8) ou um advérbio (9) que não possuem dependentes nucleares:

(7) ho:han wa:pa

gritar, vivar cachorro

"O cachorro uivou".

(8) anya adu

mulher $\quad$ ISG

"Eu sou mulher".

(9) tanti o:n

aqui sapo (gen.)

"O sapo está aqui".

Observemos os predicados em (1) e (4) novamente apresentados a seguir para comparação com os exemplos (8) e (9).
(1)
$\begin{array}{ll}\text { [dadohi] } & \text { piya } \\ \text { Correr } & \text { homem }\end{array}$
"O homem correu".
(4) [Tirin-na= [hu:na] $] \quad$ kamodya $\quad k a]$
Tirin-ERG pegar macaco barrigudo PFV
"Tirin pegou o macaco barrigudo".


A partir da comparação e análise desses exemplos, destacamos que a posição canônica do argumento interno é à esquerda de seu núcleo na construção bivalente. Para ser movido ou elidido, por exemplo, fazem-se necessárias modificações na estrutura argumental, pois não está habilitado a esses processos de forma direta.

No que se refere ao argumento externo (tanto das construções monovalente quanto das bivalentes), ele corre à direita do núcleo e acessa de forma direta processos como movimentação, elisão, entre outros. Tanto o argumento externo da construção bivalente e da monovalente exibe morfologia (não marcada) e posição sintática semelhante, isto é, estão alinhados e indicam o caso absolutivo.

Outro ponto a destacar refere-se ao argumento interno da predicação bivalente. Como foi dito anteriormente, esse apresenta morfologia casual manifestada pela associação do sintagma nominal ao enclítico -na= que indica o caso ergativo. Além disso, sua posição na sentença é diferente daquela ocupada pelos argumentos externos, isto é, à esquerda de seu núcleo.

Ao considerar o alinhamento morfossintático dos argumentos interno e externo, afirmamos que katkan é uma língua de tipo ergativo-absolutivo. Entretanto, assim como Santos (2019), identificamos uma construção de padrão nominativo-acusativo na qual o argumento interno não seleciona o enclítico $-n a=$ :

$\begin{array}{lll}\text { Pityira } & \text { hi:k } & \text { pi:da? } \\ \text { Pityira } \quad \text { ver } & \text { onça } \\ \text { "Pityira viu a onça?" } & \end{array}$

(SANTOS, 2019, p. 32)

$\begin{array}{lll}\text { Ka:ko hak } & \text { i:n } \\ \text { Ka:ko flechar } & \text { piranha } \\ \text { "Ka:ko flecha a piranha". } & \end{array}$

Nos exemplos (10) e (11), os verbos hi:k "ver" e hak "flechar" selecionam dois argumentos: um interno e outro externo. Os argumentos internos aos núcleos verbais, isto é, Ka:ko e Pityira, respectivamente, ocorrem sem a associação ao enclítico -na=. Contudo, continuam a posição à esquerda de seus núcleos. Os argumentos externos, a saber: pi:da "onça" em (10) e i:n "piranha" apresentam-se na posição à direita do núcleo e, sem marcação morfológica para caso. Sendo assim, essas construções são de tipo acusativo-nominativo.

Assumimos que as construções verbais bivalentes estão cindidas, apresentando predicados com padrão ergativo quanto acusativo. Todavia, a construção ergativa é a forma básica.

Ao concluir essa seção, frisamos que, os predicados aqui apresentados, compartilham a mesma estrutura interna e, por essa razão, dizemos que possuem isomorfia estrutural (cf. ANJOS: 2011; 2019).

Como dissemos anteriormente, a segunda parte desse artigo é dedicada aos mecanismos responsáveis pela mudança na estrutural dos predicados a partir do decréscimo da valência. 


\section{Mecanismos que modificam a estrutura argumental dos predicados}

Essa seção é dedicada à apresentação das estratégias responsáveis pelas mudanças na estrutura oracional katkan que podem gerar como resultado o aumento ou - o decréscimo da valência verbal. Nesse artigo são trabalhados os mecanismos pelos quais se decresce a valência verbal que doravante chamamos de recessivos. Existem cinco mecanismos recessivos: (i) intransitivização, (ii) reflexivo (iii) recíproco, (iv) antipassiva, e (v) incorporação nominal.

Contudo, trataremos dos processos de intransitivização, do reflexivo e do recíproco nesse artigo.

\section{Intransitivização}

O processo de intransitivização reduz a valência de um verbo mediante a utilização do sufixo -hik que doravante chamamos de intransitivizador. Ao associar esse sufixo a uma raiz verbal bivalente a diminuição da valência ocorre como é possível observar nos exemplos seguintes, nos quais figura uma construção com o verbo em sua forma básica (10a e 11a) e, em seguida, a forma com valência decrescida (1ob e 11b):

\begin{tabular}{|c|c|c|c|}
\hline \multirow[t]{2}{*}{ (10a) } & $\begin{array}{l}\text { Tamakori-na= } \\
\text { Tamakori-ERG }\end{array}$ & $\begin{array}{l}\text { topohan } \\
\text { soprar }\end{array}$ & $\begin{array}{l}\text { maripu } \\
\text { sarabatana }\end{array}$ \\
\hline & \multicolumn{3}{|c|}{ "Tamakori soprou a sarabatana". } \\
\hline (10b) & $\begin{array}{l}\text { topohan-hik } \\
\text { soprar-INTRNZ } \\
\text { "Ele soprou". }\end{array}$ & $\begin{array}{l}\text { adi:k } \\
\text { 3SG }\end{array}$ & \\
\hline$(11 a)$ & $\begin{array}{l}\text { ma-tyaman } \\
\text { 3SG-cortar } \\
\text { "Eles cortaram }\end{array}$ & $\begin{array}{l}\text { le anta } \\
\text { o da anta". }\end{array}$ & \\
\hline$(11 b)$ & $\begin{array}{l}\text { tyaman-hik } \\
\text { cortar- INTRZ } \\
\text { "Eles cortaram" }\end{array}$ & $\begin{array}{l}\text { atyian } \\
3 \mathrm{PL}\end{array}$ & \\
\hline
\end{tabular}

Os verbos bivalentes são topohan "soprar" e tyaman "cortar". Ao associarmos -hik às raízes verbais, essas passam a instituir valência 1, isto é, o verbo torna-se intransitivo como observamos em (10b) e (11b). Então, os verbos intransitivos selecionam somente um argumento externo ao núcleo expresso pelo pronome livre de $3^{a}$ pessoa singular adik "ele" para saturação da valência.

Da mesma maneira que o argumento externo das construções monovalentes, o argumento selecionado pela forma verbal intransitivizada pode ser elidido:

(10c) topohan-hik

soprar-INTRZ

"Soprou (ele)". 
(11C) tyaman-hik

cortar- INTRZ

"Cortaram (eles)".

Mesmo que não faça mais parte da construção intransitiva, o outro argumento selecionado pela forma verbal bivalente (anterior) aparece deslocado. E ocupa a posição pré-predicativa como vemos nos exemplos a seguir:

$$
\begin{array}{ll}
\text { yok-waikman } & \text { tyatyara } \\
\text { 1SG-arremessar } & \text { terçado } \\
\text { "Eu arremesso o terçado". }
\end{array}
$$

$\begin{array}{llc}\text { tyatyara } & \text { waikman-hik } & \text { adu } \\ \text { terçado } & \text { arremessar-INTRZ } & \text { ISG } \\ \text { "O terçado, eu arremesso". } & \end{array}$

\section{Reflexivo}

O segundo mecanismo recessivo é aquele que envolve a operação de reflexivo. Nesse tipo de construção, a valência semântica do verbo de uma oração bivalente é decrescida. Dessa maneira, a oração reflexiva apresenta uma entidade que ao mesmo tempo assume os papéis semânticos de agente e de paciente da ação expressa pelo verbo. Essa operação também é feita com a associação do sufixo intransitivizador -hik à raiz verbal. Assim, essa deixa de instituir valência 2 e passa a ter valência 1.

Existe uma variação alomórfica do sufixo intransitivizador -hik. Na variedade Kanamari, quando precedido por vogais, $\{$-hik\} realiza-se como $\{-k\}$. Ao ser precedido por consoante, sua realização se dá como $\{-i\}$. Na variedade Katukina do Biá tal alomorfia não foi identificada, e temos -hik $\rightarrow$ \{-hik\}.

Para saturação da valência, o verbo seleciona um argumento que possui as mesmas características formais dos argumentos externos. $\mathrm{O}$ argumento desse tipo de construção é expresso por meio de um sintagma nominal que pode ser elidido como podemos observar nos exemplos da variedade Kanamari:

$$
\begin{aligned}
(14)^{\mathrm{KAN} 2} & \text { yok-hak Nodia } \\
& \text { 1SNG-flechar Nodia } \\
& \text { "Eu flechei Nodia". }
\end{aligned}
$$

$\begin{array}{lll}(15)^{\text {KAN }} & \text { hak-i } & \text { adu } \\ & \text { flechar-INTRZ } & \text { ISNG } \\ & \text { "Eu me flechei". } & \end{array}$

2. Agradecemos ao Professor Doutor Francisco Queixalós pela disponibilização de seus dados. Utilizaremos a sigla KAN para indicar que os exemplos são oriundos da variedade Kanamari 


\section{Recíproco}

O terceiro processo recessivo a ser descrito é o recíproco. É importante pontuar que a oração recíproca apresenta semelhança conceitual com a construção reflexiva e, por essa razão, o recíproco e o reflexivo são expressos de maneira semelhante nas línguas. Como veremos, a construção recíproca utiliza o sufixo intransitivizador - $h$ ik que, também, é utilizado nas construções reflexivas como demonstramos anteriormente.

Na construção recíproca, a raiz verbal é precedida por uma forma pronominal livre too, cujo significado é "outro". Quando associamos o sufixo intransitivizador -hik ao verbo, esse passa de bivalente a monovalente e gera uma construção recíproca. Vejamos os exemplos a seguir:

$$
\begin{aligned}
& \text { Pioru-na= pu too } \\
& \text { Pioru-ERG comer outro } \\
& \text { "Pityira comeu o outro". }
\end{aligned}
$$

$\begin{array}{llll}(17)^{\text {KAN }} & \text { too } & \text { pu-k } & \text { nuk } \\ & \text { outro } & \text { comer-INTRZ } & \text { grupo }\end{array}$

"As pessoas comeram outrem".

Assim como na construção bivalente básica em (16), os dois argumentos são manifestados na construção recíproca em (17).

Convém esclarecermos qual é o estatuto do sintagma nominal too, uma forma pronominal livre. A introdução de um segundo participante nuclear tal como too "outro" na oração recíproca seria a comprovação de que essa construção não é construída tendo como modelo a construção reflexiva. Assumimos a ideia de que a construção recíproca não é feita sobre a oração reflexiva, mas sim o mecanismo de redução de valência tem como base as construções de padrão nominativo-acusativo. De acordo com essa análise, too "outro" funcionaria como um argumento genérico ocupando a posição de argumento interno num sintagma verbal bivalente contido em uma oração acusativa tal como too pu-k nuk "as pessoas ${ }_{1}$ comeram outrem," em (11). A intransitivização reflexiva passa a ser marcada com o sufixo -hik. Dessa maneira, too deixou de ser argumento da construção e tornou-se uma marca gramatical que acrescenta à construção recíproca a ideia de reflexividade (QUEIXALÓS: 2010).

\section{Considerações finais}

Nesse artigo apresentamos a descrição dos mecanismos que promovem as mudanças estruturais nos predicados katkan. Primeiramente consideramos a posição de núcleo das construções e vimos que as classes léxicas identificadas, isto é, os nomes, os verbos, as posposições e os advérbios possuem a habilidade de ocupar a posição nuclear e instituir sintagmas bem como predicados. A partir dessas considerações, observamos que a natureza do núcleo determina o tipo de predicado nessa língua. Nomes e verbos de tipo bivalentes, assim como as posposições, são núcleos que para saturar sua valência selecionam dois argumentos. Consideramos que esses predicados são a forma mais complexa nesse tipo de construção. Nomes e verbos monovalentes e, ainda, os advérbios são núcleos cuja saturação é preenchida ao selecionar um argumento. Assumimos que esses predicados são a versão mais simples da construção bivalente. 
No que se refere à estrutura interna dos predicados, mostramos que a natureza dos dois argumentos selecionados na predicação bivalente é distinta. O argumento que denominamos como interno, ocupa a posição à esquerda de seu núcleo. Quando realizado lexicalmente é constituído por um sintagma nominal que recebe marcação morfológica de caso por meio da associação do enclítico -na=. Outra forma de representar esse argumento é utilizar uma das formas do paradigma de prefixos pessoais e associa-la ao núcleo da predicação. Nos dados que analisamos, a ocorrência do prefixo pessoal bloqueia o uso de -na=, isto é, a forma prefixo pessoal-na= gera construções agramaticais.

O segundo argumento, que denominamos de externo, é selecionado pelo núcleo bivalente ocupando a posição à direita na construção prototípica, todavia podendo ser movido para direita do núcleo sem modificar e ser elidido sem modificar a estrutura argumental da oração. Convém ressaltarmos que esse argumento não recebe marcação morfológica para caso e possui as mesmas forma e características do argumento selecionado pelo núcleo monovalente, isto é, nome/verbo monovalente e advérbio.

Acerca do $-n a=$, é necessário pontuar sobre sua forma e função. Classificamos esse elemento com um enclítico, pois -na= está sintaticamente ligado ao sintagma que o precede ao passo que prosodicamente liga-se ao núcleo da predicação bivalente. Assumimos que -na= exerce diferentes funções nos predicados bivalentes, pois a natureza da relação entre o núcleo a saber nomes e verbos bivalentes e ainda as posposições e seu argumento interno é distinta. Quando o núcleo do predicado é um nome bivalente (inalienável), a relação com seu argumento, é genitiva. Já no caso do núcleo ser um verbo bivalente, a natureza da ligação com o sintagma nominal que expressa seu argumento interno é ergativa. Por fim, quando temos uma posposição como núcleo, se estabelece uma relação chamada de objeto da posposição.

Quando comparamos os argumentos externos das construções mono/bivalentes e o argumento interno do predicado bivalente, concluímos que em katkan o alinhamento morfossintático é de tipo ergativoabsolutivo, pois o argumento interno se manifesta de forma diferente dos argumentos externos e por receber marcação de caso de tipo ergativo via seleção do enclítico -na=. Entretanto, os argumentos externos não recebem marca morfológica e indicam o caso absolutivo.

Todavia, identificamos um tipo de construção verbal bivalente (menos frequente) na qual o argumento interno não recebe marcação casual. Assim sendo, classificamos essa construção como sendo de tipo nominativo-acusativo. Então assumimos que as construções verbais bivalentes estão cindidas, pois há construções ergativas e construções acusativas.

A segunda parte do artigo tratou dos processos que diminuem a valência verbal e modificam a estrutura argumental dos predicados que chamamos de mecanismos recessivos. Foram apresentados, neste artigo, três processos que utilizam o sufixo -hik: intransitivização, reflexivo e recíproco. O mecanismo de intransitivização diminui a valência verbal de tipo 2 para tipo 1. Para isso, associamos à raiz verbal o sufixo -hik denominado intransitivizador. Para comprovar esse processo basta observar que o verbo intransitivizado agora passa a selecionar somente um argumento para saturação da valência e esse argumento pode ser elidido tal qual o argumento da construção monovalente.

Na construção reflexiva, a valência semântica do verbo de uma oração bivalente é decrescida. Assim, a oração reflexiva apresenta uma entidade que ao mesmo tempo assume os papéis semânticos de agente e de paciente da ação expressa pelo verbo mediante a associação de -hik à raiz verbal.

Nesse sentido, ratificamos que, apesar da utilização de -hik, existem diferenças entre as construções 
recíproca e reflexiva em katkan. Na estrutura de tipo reflexiva, a raiz verbal é precedida por uma forma pronominal livre too, cujo significado é "outro". Quando associamos o sufixo intransitivizador -hik ao verbo, esse passa de bivalente a monovalente e gera uma construção recíproca. Assumimos a análise de Queixalós (2010) acerca da construção reflexiva e do pronome livre too "outro". Para o autor, o pronome livre funciona como um argumento genérico e ocupa a posição de argumento interno num sintagma verbal bivalente contido em uma oração acusativa tal como too pu-k nuk "as pessoası comeram outrem1", como exposto no exemplo (11). A intransitivização reflexiva passa a ser marcada com o sufixo -hik. A forma pronominal too deixa de ser argumento da construção e torna-se uma marca gramatical que acrescenta à construção recíproca a ideia de reflexividade.

\section{Referências}

AIKENVALD, Alexandra. Versatile Cases. Linguistics: 44. Cambridge: Cambridge University Press, 2008, p. 565-603.

AIKENVALD, Alexandra.Transitivity in Tariana. In: DIXON, Robert. ; AIKENVALD, Alexandra. Changing valency Cases studies of transitivity. Cambridge: Cambridge University Press, 2000, p. 145-172.

ANJOS, Zoraide. Fonologia e Gramática Katukina-Kanamari. 2011. Tese (Doutorado). Utrecht: LOT, 2011.

ANJOS, Zoraide. Fonologia Katukina-Kanamari. Liames, v. 12, Campinas, Unicamp, 2012, p. 123-156.

ISHY, Priscila. Kanamari do Juruá (família Katukina) - Aspectos fonológicos e morfossintáticos. 2018. Tese (Doutorado em Linguística), Universidade Estadual de Campinas, Campinas/SP, 2018.

ISHY, Priscila. Uma Análise Fonológica da Língua Kanamari (Katukina). 2021. Dissertação (Mestrado em Linguística). Universidade Estadual de Campinas, Campinas/SP, 2012.

QUEIXALÓS, Francisco. Grammatical relations in Katukina-Kanamari. In: GILDEA, Spike.; QUEIXALÓS, Francisco.(eds.) Ergativity in Amazonia. Amsterdã: John Benjamins Publishing Company, 2010.

QUEIXALÓS, Francisco. Posse em Katukína e valência dos nomes. In: RODRIGUES, Aryon. \& CABRAL, Ana Suely. (orgs.) Novos estudos sobre línguas indígenas brasileiras. Brasília: Editora Universidade de Brasília, 2005, p. 177-202.

QUEIXALÓS, Francesc. Valence in Katukina-Kanamari noun phrases and the nature of genitive classifiers. In: QUEIXALÓS, Francesc. \& GOMES, Dioney M. (eds.). Sintagma Nominal em línguas amazônicas. Campinas/SP: Pontes, 2017, p. 141-176.

QUEIXALÓS, Francisco; ANJOS, Zoraide. A língua Katukína-Kanamarí, in: Liames, v. 6, Campinas: Unicamp, 2007, p. 20-60.

SANTOS, Edite Consuêlo. O estatuto da ergatividade na língua Katukina-Kanamari. 2019. Tese (Doutorado). Universidade Federal de Pernambuco, Recife, 2019. 